\title{
TIMED Doppler Interferometer (TIDI) Observations of Migrating Diurnal and Semi-diurnal Tides
}

\author{
${\text { Qian } \mathrm{Wu}^{1} \text {, T. L. Killeen }}^{1}$, D. A. Ortland ${ }^{2}$, S. C. Solomon ${ }^{1}$, \\ R. D. Gablehouse ${ }^{1}$, R. M. Johnson ${ }^{1}$, W. R. Skinner ${ }^{3}$, R. J. Niciejewski ${ }^{3}$, S. J. Franke ${ }^{4}$ \\ ${ }^{1}$ High Altitude Observatory \\ National Center for Atmospheric Research \\ P. O. Box 3000 \\ Boulder, CO 80307-3000 \\ ${ }^{2}$ Northwest Research Associates \\ P. O. Box 3027 \\ Bellevue, WA 98009-3027 \\ ${ }^{3}$ Space Physics Research Laboratory \\ The University of Michigan \\ 2455 Hayward St. \\ Ann Arbor, MI 48109-2143 \\ ${ }^{4}$ Department of Electrical and Computer Engineering \\ University of Illinois \\ Urbana, IL 61802
}

\begin{abstract}
Based on zonally averaged TIDI meridional wind data from one yaw period (2004079 - 140) during equinox, we examine the latitudinal and altitudinal distribution of the migrating diurnal and semi-diurnal tides using least squares fitting method to provide a global view of these tidal waves. The TIDI results are compared with Global Scale Wave Model 00 output for the month of April. The diurnal tide amplitude distribution and are in a good agreement. The TIDI results show a lower peak altitude $(97 \mathrm{~km})$ while GSWM00 peaks at $102 \mathrm{~km}$. The vertical wavelength from the TIDI is about $20 \mathrm{~km}$ while the model predicts $25 \mathrm{~km}$. The semi-diurnal tide comparisons are also reasonable. Both model and TIDI data show peak amplitudes at $45^{\circ}$ latitude. The TIDI meridional winds compare very well with ground based meteor radar measurements at Maui. The zonal wind discrepancies are not unexpected.
\end{abstract}

\section{Introduction}

Migrating tides are the most prominent features in the mesosphere and lower thermosphere (MLT) region. Understanding tidal wave generation, propagation, and interactions with gravity waves and planetary waves is the key to the insight of the dynamics and energetics of the MLT region. There is a long history of tidal wave study starting with the classical tidal theory (e.g., Chapman and Lindzen, 1970). Tides are also affected by advection, background mean neutral winds, nonlinear interaction between different tidal modes, and the geographic distribution of latent heat release. Various numerical tidal models have been developed to simulate these effects (e.g, Forbes, 1982a,b; Vial 1989; Forbes and Hagan, 1988; Hagan et al., 1995; Hagan and Roble, 2001; Hagan and Forbes, 2002; 2003). 
Early observations of MLT tides were made by ground based instruments (Fabry-Perot interferometer, lidar, meteor radar, MF radar, and incoherent scatter radar) and rocket. Since tides are global scale waves, it is impossible for observations from a single ground station to provide an overall picture of the wave. Therefore, multiple-station observations are often used to examine tides. One example of such an effort is the PSMOS (Planetary Scale Meospause Observing System) project, in which many investigators participated using ground-based radars around the world (e.g., Pancheva et al., 2002). These observations have revealed a great deal about the various tidal modes in the mesosphere and lower thermosphere. Nevertheless, the deployment of ground-based instruments is limited by the geography, because $70 \%$ of the Earth's surface is covered by ocean. The usage of multiple instrument data sets also raises the issue of inter-instrument calibration.

The introduction of satellite observations of mesosphere and lower thermosphere neutral wind brought a new perspective to the study of upper atmosphere tides, because satellite observations can provide nearglobal coverage. The Upper Atmospheric Research Satellite (UARS) High Resolution Doppler Interferometer (Hays et al., 1993) and Wind Imaging Interferometer (Shepherd et al., 1993) have provided a much better global view of tides. Migrating tides were studied based on data sets from these two instruments (Morton et al., 1993; Lieberman and Hays, 1994; Hays et al., 1994; Burrage et al., 1995a; Burrage et al., 1995b; McLandress et al., 1996; Khattatov et al., 1997a; b; Huang and Reber, 2003). Yet UARS observations did not provide coverage over high latitude regions, because of its orbital inclination. Moreover HRDI provided only single altitude (at $95 \mathrm{~km}$ ) observation on the nightside. Consequently, the tidal analysis was hampered somewhat by the limited local time and altitude coverages.

To provide a better pole-to-pole coverage for the study of the MLT dynamics and energetics, on December 7, 2001, TIMED (Thermosphere Ionosphere Mesosphere Energetics and Dynamics) satellite was launched into orbit. TIMED is a two-year mission sponsored by NASA to study the mesosphere and lower thermosphere, which provide a crucial link between solar activity and the Earth. The satellite is in a near circular orbit with $625 \mathrm{~km}$ altitude, $74.1^{\circ}$ inclination, and a $3^{\circ}$ per day precession rate. Approximately every 60 days, a $180^{\circ}$ yaw maneuver of the satellite is performed to avoid the sunlight shining onto the cold side of the spacecraft. There are four instruments onboard the TIMED satellite (TIMED Doppler Interferometer, Global Ultraviolet Imager, Sounding of the Atmospheric Using Broadband Emission Radiometry, Solar Extreme Ultraviolet Experiment). The TIMED Doppler Interferometer (TIDI) was designed to measure the neutral winds in the mesosphere and lower thermosphere. In this report, we describe the TIDI measurements of the migrating diurnal and semidiurnal tides in the MLT region. This paper is organized as follows: We briefly describe the instrument in the next section. The TIDI data analysis method and results are next. Comparisons with Global Scale Wave Model (GSWM00) output and ground based meteor radar measurements are presented. Finally we summarize our findings.

\section{Instrument}

The TIDI instrument was developed and built by the University of Michigan (Killeen et al, 1999). TIDI measures neutral winds by performing limb scans of various upper atmosphere airglow layers and monitoring the Doppler shift of airglow emissions induced by neutral winds. It traces its roots to earlier Fabry-Perot interferometers onboard satellites such as Dynamic Explorer 2 (Hays et al., 1981; Killeen and Hays, 1982) and UARS (Hays et al., 1993). TIDI is a more sensitive instrument with four telescopes, a circle to line interferometer (CLIO) conical mirror, and a CCD detector with quantum efficiency exceeding $60 \%$ at some wavelengths. One reason for the high sensitivity is due to the multiplexing advantage of the simultaneous recording of spectra from all four telescopes. The CLIO further reduces the readout noise of the CCD by removing the need to sample individual pixels (Hays, 1990). 
The four TIDI telescopes are orthogonally oriented, allowing the instrument to measure neutral wind vectors on both sides of the satellite track. The two telescopes viewing the same side of the track observe the same locations with a time delay of a few minutes as the spacecraft moves forward. The viewing directions of these two telescopes are perpendicular to one another. Assuming that the neutral winds do not change much during the short time period, the samplings at the two directions can then be used to form the neutral wind vector in terms of the meridional and zonal components.

The local time coverage on day 2004080 is shown in Figure 1. There are four local time samplings at latitudes equatorward of $\pm 60^{\circ}$ and two at latitudes poleward of $\pm 60^{\circ}$. The local time coverage pattern shifts slowly (by $0.2 \mathrm{hr} /$ day) towards earlier local times as time progresses. The satellite orbits the Earth 15 times (98 minutes per orbit), and the local time of the orbit will not change much within a day. As the Earth rotates under the TIMED orbit, TIDI provides longitudinal coverage around the globe. The single black arrow indicates the flight direction of the satellite. The two-head arrows mark the hemispheres where the coldside (southern) or warmside (northern) samplings provide equator to pole coverage with similar local times. The four telescopes scan the $\mathrm{O}_{2}(0-0)$ airglow emissions P9 line in a repeating sequence called a scan cycle, which defines the operational mode. TIDI has both daytime and nighttime operational modes. Typical day and nighttime operational modes of TIDI take about 105 seconds to complete and TIDI repeats the same scan pattern until the spacecraft crosses the day/night boundary. The 100 seconds temporal resolution translates to about $7^{\circ}$ latitudinal grid for spatial coverage. The TIDI coverage extends from the middle atmosphere to the upper mesosphere and lower thermosphere. The nighttime coverage is narrower due to the more limited altitude range of nightglow emissions.

\section{TIDI Data Analysis}

The data processing procedure comprises three stages. In the first stage, the TIDI spectral data are merged with spacecraft orbital information to form Level 1 spectral data. The spectral data are processed to remove the various backgrounds and then normalized to physical units of Rayleigh $/ \mathrm{cm}^{-1}$ for each spectral channel. Line-of-sight winds are computed without any inversion algorithm. In the second stage, the spectral data are inverted in altitude to form line-of-sight inverted winds (Level 2 data). In the final stage, the inverted line-of-sight winds from different telescopes are combined to form neutral wind vectors in terms of meridional and zonal components (Level 3).

TIDI experienced some anomalies after the launch, namely the ice buildup on instrument optical surfaces and higher than expected background (Skinner et al., 2003). The ice buildup on optical surface caused strong cross-talk between telescope fields and reduction in the instrument throughput. Fortunately, the ice buildup has been reduced by two roll maneuvers, during which the satellite coldside was tilted towards the warmer Earth surface and away from the much colder deep space. In turn, the instrument was warmed up to allow ice to sublimate. The cause of the high background is likely due to the leak on the back of the instrument, which allows Earth's reflection of the sunlight to enter the instrument and registered on the instrument detector. The cause for the high background was later confirmed by the close resemblance between the background intensity map and cloud cover pattern on the Earth's surface (Skinner et al. 2003). To remove the highly varying background, TIDI periodically samples backgrounds, which are represented in terms of Empirical Orthogonal Functions (EOF). The EOFs are calculated from a large collection of background samples. The backgrounds for spectral data between background samples are estimated by interpolation of the amplitudes of the EOF of the measured backgrounds according to the data sampling times. These procedures have been implemented into the daily data production software.

The zonally averaged data taken on day 2004080 are shown in Figure 2. The zonal average is performed on a $5^{\circ}$ degree satellite track angle grid. The upper two panels show the neutral winds from the coldside 
and lower panels show the data from the warmside. The meridional winds are in panels on the left side and zonal on the right. Within each panel, the neutral winds from the ascending (left) and descending (right) nodes are plotted. During this day, the ascending node is on the nightside, as indicated by the narrower altitude range and descending node is on the dayside. Because of the relatively slow precession rate ( $3^{\circ}$ per day), measurements from 15 orbits during a day are at about the same local times. Hence, zonally averaging the 15 orbits can reduce non-migrating tide contributions and enhance the migrating tides, because migrating tides are longitudinally independent. For this analysis we mainly study the meridional winds. The meridional winds in Figure 2 show clear signs of the migrating diurnal tide with its anti-symmetric wind pattern about the equator. The vertical feature also indicates the vertical wavelength of the migrating diurnal tides is about $20 \mathrm{~km}$. In this study we use portions of the satellite samplings marked by the green arrows from the coldside (southern hemisphere) and warmside (northern hemisphere) to extract the migrating diurnal and semi-diurnal tides. These portions of the measurements are also highlighted in Figure 1. We used these segments because they provide similar local time coverage from the equator to the pole in each of the hemisphere. We combined the data from a complete yaw period from day 2004079 to 20040140 . Hence, we have complete 24-hour local time coverage from 60-day of observation. We selected this yaw period because this is a period of equinox, when the migrating diurnal tide tends to be strong (Hays et al., 1994). Figure 3 shows the meridional winds from three latitudes in the northern hemisphere based on observations during this yaw period. The neutral winds at $11.29^{\circ} \mathrm{N}$ (the upper panel) show prominent positive and negative bands with a slope of local time variation consistent with a diurnal tide. The neutral winds at $30.35^{\circ} \mathrm{N}$ (the middle panel) also show strong diurnal tide, however, the tilt is slightly steeper probably due to the influence of the semi-diurnal tide. The neutral winds at $44.79^{\circ} \mathrm{N}$ are shown in the lower panel and the neutral winds contains mainly the semi-diurnal tide as the faster local time variation indicated.

Assuming that the tidal amplitude and phase did not change dramatically during this time period, then we can least squares fit the meridional wind data from this yaw period at different latitudes and altitudes with a background wind, a diurnal oscillation, and a semi-diurnal oscillation to extract the migrating diurnal and semi-diurnal tide parameters. In this way, we can estimate the latitudinal and altitude distribution of the migrating diurnal and semi-diurnal tides without assuming any composition of tidal modes. This method, however, has several drawbacks. First, the tidal amplitude may not be constant over the 60 days, hence this is an averaged result. Second the mean winds may also change during the yaw period and introducing additional day-to-day variations, which are treated as local time variation in our analysis. Since the diurnal tidal amplitude is so large during equinox, these variations should not affect the final results significantly.

Figure 4 shows the least square fitting results for the diurnal and semi-diurnal tides. The northern hemisphere is from the warmside and southern from the coldside. The upper left panel is for the diurnal tide amplitude and lower left is for the diurnal tide phase. Near the equator the diurnal tide amplitude forms a nearly symmetric butterfly pattern, while the phases are nearly $180^{\circ}$ off between the two hemispheres. The amplitude is about $70 \mathrm{~m} / \mathrm{s}$ and peaks between 95 and $100 \mathrm{~km}$. This is the typical diurnal tide $(1,1)$ mode pattern indicating that this is the most prominent mode in the migrating diurnal tide. The large amplitude at southern high latitudes is probably due to the difficulty inverting twilight limb scan data. Limb scan data inversion assumes horizontal homogeneity, which does not hold true near twilight. Polar regions during equinox are under twilight condition. It should be noted that the diurnal tide amplitude during the equinox is similar to what was observed by UARS HRDI (Hays et al, 1994, Burrage et al, 1995). While we are more focused on latitudinal and altitudinal variation of the diurnal tide, the HRDI analysis was more concerned about the daily variation through fitting the daily zonally averaged data with assumed altitude and latitude variation of diurnal tide $(1,1)$ mode. McLandress et al. (1996) obtained similar results for the diurnal tide latitude and altitude distribution based on UARS WINDII data, though limited between the $40^{\circ} \mathrm{S}$ and $40^{\circ} \mathrm{N}$ latitudes. 
The upper right panel shows the semi-diurnal tide amplitude and lower right is for the semi-diurnal tide phase. In the northern hemisphere the semi-diurnal tide amplitude peaks around $45^{\circ} \mathrm{N}$. The amplitude is about $40 \mathrm{~m} / \mathrm{s}$. In the southern hemisphere, the semi-diurnal tide amplitude from the TIDI data is much stronger. The semi-diurnal tide results from the southern hemisphere may not be as reliable as those from the northern hemisphere. The southern hemisphere measurements are from the coldside. We have noted that during twilight conditions (dawn and dusk), the coldside winds are apparently strongly affected. Twilight condition can affect both the warmside and coldside. The coldside is more affected because the coldside data were taken by the satellite from the terminator looking into the nightside. To accommodate the warmside, which is viewing the dayside, the integration time and detector gain setting are all set for the dayglow data. The coldside data on the other are more nightglow like. Hence, the coldside data tend to be under exposed during twilight condition. Consequently, the coldside data have a tendency to be more affected during the twilight condition than the warmside. Therefore, these strong semi-diurnal tide amplitudes from the southern hemisphere may be artifacts from the affected winds during the twilight condition. Further study is underway to resolve the issue. A comparison with UARS HRDI results (Burrage et al., 1995a) shows the TIDI northern hemisphere results are similar to the HRDI results, which were limited to $95 \mathrm{~km}$ altitude. It should be pointed out that TIDI is the first instrument that is able to show the latitude (pole to pole) and altitude profile for the semi-diurnal tide amplitude and phase.

\section{Comparisons with the GSWM00 model output}

Tidal wave modeling effort has been on going for some time. The NCAR/HAO Global Scale Wave Model (GSWM) has gone through many improvements (Hagan et al., 1995; 1999; Hagan and Roble 2001). The latest GSWM02 (Hagan and Forbes, 2002; 2003) also include the effect of the tropospheric latent heat release and non-migrating tide components. For our purposes, we used GSWM00 (Hagan and Roble, 2001), which is the same as the GSWM02 except for not including the latent heat release and nonmigrating tide component, which we are not considering at this point. Moreover the GSWM00 results are readily available on the web. We plotted the migrating diurnal and semi-diurnal tides for the month of April in Figure 5 using the same format as TIDI data in Figure 4 for easy comparison. The diurnal tide amplitude is similar to that observed by TIDI. The shape of the amplitude distribution is also a close match of that from TIDI. The peak altitude in the GSWM00 is higher than (between 100 and $105 \mathrm{~km}$ ) that from the TIDI (between 95 and $100 \mathrm{~km}$ ). Though not clearly shown here, the vertical wavelength $(\sim 25 \mathrm{~km})$ from the GSWM00 is also longer than that from the TIDI results $(\sim 20 \mathrm{~km})$. It should be noted that McLandress et al. (1996) also showed that the UARS observed peak altitude was also lower than the model prediction from the GSWM95 (Hagan et al., 1995).

The semi-diurnal tide from the GSWM00 show strong peaks centered at $45^{\circ} \mathrm{S}$ and $45^{\circ} \mathrm{N}$, which are at similar locations where the TIDI data peaked. The amplitude is stronger in the northern hemisphere for the GSWM00 and weaker in the southern hemisphere for the model.

\section{Comparison with Ground-based meteor radar}

In the past satellite measurements of neutral winds have been compared with ground-based observations with mixed results (Burrage et al., 1996). Some ground-based measurements agreed with the satellite measurements better than others. Meridional wind component tends to have better agreement than the zonal component and the cause is still a mystery (Forbes et al., 2004). Nevertheless, such comparisons are necessary for both the ground-based instruments and satellite observations, because they can help reveal each other's merits and weaknesses and help improve the data processing procedures for both sides. For this analysis, we selected the ground-based meteor radar from Maui $\left(20^{\circ} \mathrm{N}\right)$ for comparison. The radar was selected for the following reasons: 1) it provides 24-hour coverage; 2) its location is where the diurnal tide peaks, thus it can provide large range for the wind; 3) the meteor is co-located with a 
sodium lidar and the radar results have been cross-calibrated with the lidar (Franke et al., 2004). Figure 6 shows the data from meteor radar on March 1, 2004. The upper left panel records the meteor hit during the day. The lower left panel shows the zonal wind and lower right shows the meridional wind. A strong diurnal oscillation is clearly visible in both components. Since the TIDI instrument warmside (we use only warmside for the northern hemisphere) sample only two local times each day, we selected the meteor data according to the TIDI overpass times on each day during the yaw period (day 200479-140) and composed the multi-day sampled 24-hour local time data set for the TIDI comparison. The meridional and zonal winds for the data are plotted in Figure 7. Not surprisingly both the meridional (upper panel) and zonal winds (lower panel) show the same positive and negative bands with a slope matching a diurnal variation. The TIDI meridional and zonal winds (from $20^{\circ} \mathrm{N}$ ) are shown in Figure 8. As has been reported earlier that the meridional winds tend agree better between satellite measurements and ground based observations (Forbes et al., 2004). The zonal winds show some discrepancies. The zonal wind data near dawn and dusk show some very strong winds, which are probably caused by twilight condition and are not real. Overall, the two data sets show reasonable agreement for the meridional winds. It demonstrates that the TIDI results are consistent with ground-based measurement in a more general sense, because the meteor radar has been cross-calibrated with the co-located sodium lidar.

\section{Summary}

In this report, we analyzed zonally averaged TIDI neutral wind data from one yaw period 2004079 to 2004140 during equinox. The multi-day data set provides 24-hour local time coverage, which allows the extraction of diurnal and semi-diurnal tides. The TIDI data provided good latitudinal and altitudinal coverages of the migrating diurnal and semi-diurnal tide amplitude and phase. The TIDI results are compared with GSWM00 output for the month of April. The TIDI diurnal tide results agree with the GSWM00 output very well. Both show symmetric butterfly pattern for the tidal amplitude center at the equator indicating strong $(1,1)$ mode contribution. Subtle differences, however, do exist. For example the diurnal tide amplitude peaked at an altitude lower than the model predicted by $5 \mathrm{~km}$. The vertical wavelength for the TIDI results also a bit shorter than that shown in the model. The TIDI data can help to refine the model parameters in the future. The semi-diurnal tide so far is still a work in progress. The TIDI results do resemble the model output in some aspects. For example, the both appear to show the semi-diurnal tide peaks at $45^{\circ}$ latitude. The comparison with ground-based meteor radar shows encouragingly good results for the meridional winds. Some discrepancies in the zonal winds are not unexpected. These comparisons give more credence to the TIDI neutral wind results. Other studies with TIDI neutral winds are on going, we will report more results in the near future.

\section{Acknowledgments}

This research is supported by NASA grant NAG5-5334 to the National Center for Atmospheric Research (NCAR) and grant NAG5-5049 to the University of Michigan. NCAR is supported by the National Science Foundation. The Maui meteor radar operation is supported by National Science Foundation grants ATM 00-03182 and ATM 00-3198.

\section{References}

Burrage, M. D., D. L. Wu, W. R. Skinner, D. A. Ortland, and P. B. Hays, 1995a, Latitude and seasonal dependence of the semidiurnal tide observed by the high resolution Doppler imager, J. Geophys. Res. 100, 11313-11321. 
Burrage, M. D., M. E. Hagan, W. R. Skinner, D. L. Wu, and P. B. Hays, 1995b, Long-term variability in the solar diurnal tide observed by HRDI and simulated by the GSWM, Geophys. Res. Lett., 22, 26412644.

Burrage, M. D., W. R. Skinner, D. A. Gell, P.B. Hays, A. R. Marshall, D. A. Ortland, A. H. Manson, S. J. Franke, D. C. Fritts, P. Hoffman, C. McLandress, R. Niciejewski, F. J. Schmidlin, G. G. Shepherd, W. Singer, T. Tsuda, and R. A. Vincent, 1996, Validation of mesosphere and lower thermosphere winds from the high-resolution Doppler imager on UARS, J. Geophys. Res., 101, 10,365,10,392.

Chapman, S. and R. S. Lindzen, 1970, Atmospheric tides, Gordon and Breach, pp. 200, Newark, NJ.

Forbes, J. M., 1982a, Atmospheric tides, 1, Model description and results for the solar diurnal component, J. Geophys. Res., 87, 5222-5240.

Forbes, J. M., 1982b, Atmospheric tides, 2, The solar and lunar semidiurnal components, J. Geophys. Res., 87, 5241-5252.

Forbes, J. M. and M. E. Hagan, 1988, Diurnal propagating tide in the presence of mean winds and dissipation: A numerical investigation, Planet. Space Sci., 36, 579-590.

Forbes, J. M., Yu. I. Portnyagin, W. Skinner, R. A. Vincent, T. Solovjova, E. Merzlyakov, T. Nakamura, and S. Palo, 2004, Climatological lower thermosphere winds as seen by ground-based and space-based instruments, Ann. Geophy., 22, 1931-1945.

Franke, S. J., X. Chu, A. Z. Liu, W. K. Hocking, Comparison of meteor radar and Na Doppler lidar measurements of winds in the meospause region above Maui, HI, submitted to J. Geophys. Res., 2004.

Hagan, M. E., J. M. Forbes, and F. Vial, 1995, On modeling migrating solar tides, Geophys. Res. Lett, 22, 893-896.

Hagan, M. E. M. D. Burrage, J. M. Forbes, J. Hackney, W. J. Randel, and X. Zhang, 1999, GSWM-98: Results for migrating solar tides, J. Geophys. Res., 104, 6813-6827.

Hagan, M. E. and R. G. Roble, 2001, Modeling diurnal tidal variability with the National Center for Atmospheric Research thermosphere-ionosphere-mesosphere-electrodynamics general circulation model, J. Geophys. Res., 106, 24,869-24,882.

Hagan, M. E. and J. M. Forbes, 2002, Migrating and nonmigrating diurnal tides in the middle and upper atmosphere excited by tropospheric latent heat release, J. Geophys. Res.,107, doi:10.1029/2001JD001236.

Hagan, M. E. and J. M. Forbes, 2003, Migrating and nonmigrating semi-diurnal tides in the upper atmosphere excited by tropospheric latent heat release, J. Geophys. Res.,108, doi:10.1029/2002JA009466.

Hays, P. B., T. L. Killeen, and B. C. Kennedy, 1981, The Fabry-Perot Interferometer on Dynamics Explorer, Space Sci. Instrum., 5, 395-416.

Hays, P. B., V. J. Abreu, M. E. Dobbs, D. A. Gell, H. J. Grassl, and W. R. Skinner, 1993, The High Resolution Doppler Imager on the Upper Atmospheric Research Satellite, J. Geophys. Res., 98, 10,713$10,723$. 
Hays, P. B., D. L. Wu, M. D. Burrage, D. A. Gell, H. J. Grassl, R. S. Lieberman, A. R. Marshall, Y. T. Morton, D. A. Ortland, W. R. Skinner, 1994, Observations of the diurnal tide from space, J. Atmos. Sci. 51, 3077-3093.

Hays, P. B., 1990, Circle to line interferometer optical system, Applied Optics, 29, 1482-1489.

Huang, F. T. and C. A. Reber, 2003, Seasonal behavior of the semi-diurnal tides and mean flows at 95 $\mathrm{km}$, based on measureuments from the High Resolution Doppler Imager (HRDI) on the Upper Atmospheric Research Satellite (UARS), J. Geophys. Res., 108, doi:10.1029/2002JD003189.

Khattatov, B. V. V. A. Yubin, M. A. Geller, P. B. Hays, R. A. Vincent, 1997a, Diurnal migrating tide as seen by the high resolution Doppler imager/UARS 1. Monthly mean global meridional winds, J. Geophys. Res., 102, 4405-4422.

Khattatov, B. V., M. A. Geller, V. A. Yubin, P. B. Hays, 1997b, Diurnal migrating tide as seen by the high resolution Doppler imager/UARS 2. Monthly mean global zonal and vertical velocities, pressure, temperature, and inferred dissipation, J. Geophys. Res., 102, 4423-4435.

Killeen, T. L. and P. B. Hays, 1982, Doppler line profile analysis for a multi-channel Fabry-Perot interferometer, Appl. Opt., 23, 612-620.

Killeen, T. L., W. R. Skinner, R. M. Johnson, C. J. Edmonson, Q. Wu, R. J. Niciejewski, H. J. Grassl, D. A. Gell, P. E. Hanson, J. D. Harvey, J. F. Kafkalidis, 1999, TIMED Doppler Interferometer (TIDI), Proc. SPIE 3756, 289-301, Optical Spectroscopic Techniques and Instrumentation for Atmospheric and Space Research III, Allen M. Larar Ed.

Lieberman, R. S. and P. B. Hays, 1994, An estimate of the momentum deposition in the lower thermosphere by the observed diurnal tide, J. Atmos. Sci., 51, 3094-3105.

McLandress, C., G. G. Shepherd, and B. H. Solheim, 1996, Satellite observations of thermospheric tides: Results from the Wind Imaging interferometer on UARS, J. Geophys. Res., 101, 4093-4114.

Morton, Y. T. R. S. Lieberman, P. B. Hays, D. A. Ortland, A. R. Marshell, D.L. Wu, W. R. Skinner, M. D. Burrage, D. A. Gell, and J. -H. Yee, 1993, Global meosospheric tidal winds observed by the high resolution research satellite, Geophys. Res. Lett., 20, 1263-1266.

Pancheva, D, E. Merzlyakov, N. J. Mitchell, Y. Portnyagin, A. H. Manson, C. Jacobi, C. E. Meek, Y. Luo, R. R. Clark, W. K., Hocking, J. MacDougall, H. G. Muller, D. Kurschner,G. O. L. Jones, R. A. Vincent, I. M. Reid, W. Singer, K. Igarashi, G. I. Fraser, A. N. Fahrutdinova, A. M. Stepanov, L. M. G. Poole, S. B. Malinga, B. L. Kashcheyev, A. N. Oleynikov, 2002, Global-scale tidal variability during the PSMOS campaign of June-August 1999: interaction with planetary waves, J. Atmos. Sol.-Terr. Phys., 64, $1865-1896$.

Shepherd, G. G., G.Thuillier, W. A. Gault, B. H. Solheim, C. Herscom, J. M. Alunni, J. F. Brun ,S. Brune, P. Charlot, L. L. Cogger, D. L. Desaulniers, W. F. J. Evans, R. L. Gattingerm, F. Girod, D. Harvie, R. H. Hum, D. J. W. Kendall, E. J. Llewellyn, R. P. LOWE, J. Ohrt, F. Pasternak, O. Peillet, I. Powell, Y. Rochon, W. E. Ward, R. H. Wiens, J. Wimperis, 1993, WINDII, The WIND Imaging Interferometer on the Upper-Atmosphere Research satellite, J. Geophys. Res. 98, 10,725-10,750. 
Skinner, W. R., R. J. Niciejewski, T. L. Killeen, S. C. Solomon, R. D. Gablehouse, Q. Wu, D. Ortland, D. A. Gell, A. R. Marshall, E. Wolfe Jr., M. Cooper, J. F. Kafkalidis, 2003, Operational Performance of the TIMED Doppler Interferometer (TIDI), Proc. SPIE, 5157, 47-57.

Vial, F., 1989, Tides in the middle atmosphere, J. Atmos. Terr. Phys., 51, 3-17.

\section{Figure Captions}

Figure 1. Local time and latitude coverage during day 2004080 at $85 \mathrm{~km}$ altitude.

The red (blue) is for the warmside (coldside). The open (closed) symbols are for the daytime (nighttime) sector. The single black arrow point toward the satellite flying direction. The two-head arrows mark the segments of the data where warmside (coldside) for the northern (southern) hemisphere provides nearly similar local time from the equator to the pole. These data segment are later used in the analysis.

Figure 2. Zonally averaged meridional and zonal winds from the coldside and warmside. The coldside (warmside) data are shown in upper (lower) panels. The meridional winds are on the left and zonal on the right. Inside each panel, the ascending node is on the left and descending node is on the right. The ascending node on this day was in the nighttime and descending node in the daytime. The green arrows in the meridional wind panels marks the same data segment highlighted in Figure 1. These segments are later used for the tidal analysis.

Figure 3. Meridional winds during one yaw period from three northern latitudes. The data from 11.29, 30.36, and 44.79 latitudes are shown from upper to lower panels. The rightside (12-24 LT) is from ascending node and leftside (0-12 LT) is from the descending node. At the beginning of the yaw period (day 2004079) the ascending node is near midnight and as the day progresses and local time for sampling moves backward toward earlier hours. Near the end of the yaw period (day 2004140), the ascending node has moved from midnight to near local noon. The descending node starts near local noon and moves backward to the midnight at the end of the yaw period. It should be noted that the warmside will never sample the midnight sector because of the yaw maneuver. At the same time, the coldside will never sample the local noon sector.

Figure 4. Least squares fit results of diurnal and semi-diurnal tide amplitude and phase. The least squares fit using a background wind, a diurnal oscillation, and semi-diurnal oscillation for data taken at different latitudes and altitudes. The diurnal tide amplitude (upper left) and phase (lower left) are displayed. The semi-diurnal amplitude (upper right) and phase (lower right) are also shown. The northern (southern) hemisphere results are from the warmside (coldside).

Figure 5. The GSWM00 output of diurnal and semi-diurnal tide amplitude and phase for the month of April. The plot is in the same format as Figure 4. 
Figure 6. Meteor radar neutral wind data on March 1, 2004. The number of meteor hit is recorded in the upper left panel. The meridional (zonal) winds are plotted in the lower right (left) panel.

Figure 7. Multi-day composite of local time variation of the neutral wind for the yaw period (20040792004140) from Maui meteor radar. From day 2004079 to day 2004140, TIDI warmside pass over Maui twice a day (on ascending and descending nodes separated by about 12 hours), the Maui data were selected according to these overpass times and combined to form this data set for comparison with TIDI data.

Figure 8. TIDI measurements of the neutral wind at $20^{\circ} \mathrm{N}$. The plot is in the same format as Figure 7. The TIDI data are sampled at the same local time and day as the Maui data shown in Figure 7. 
TIDI Orbital LT Coverage Day 2004080

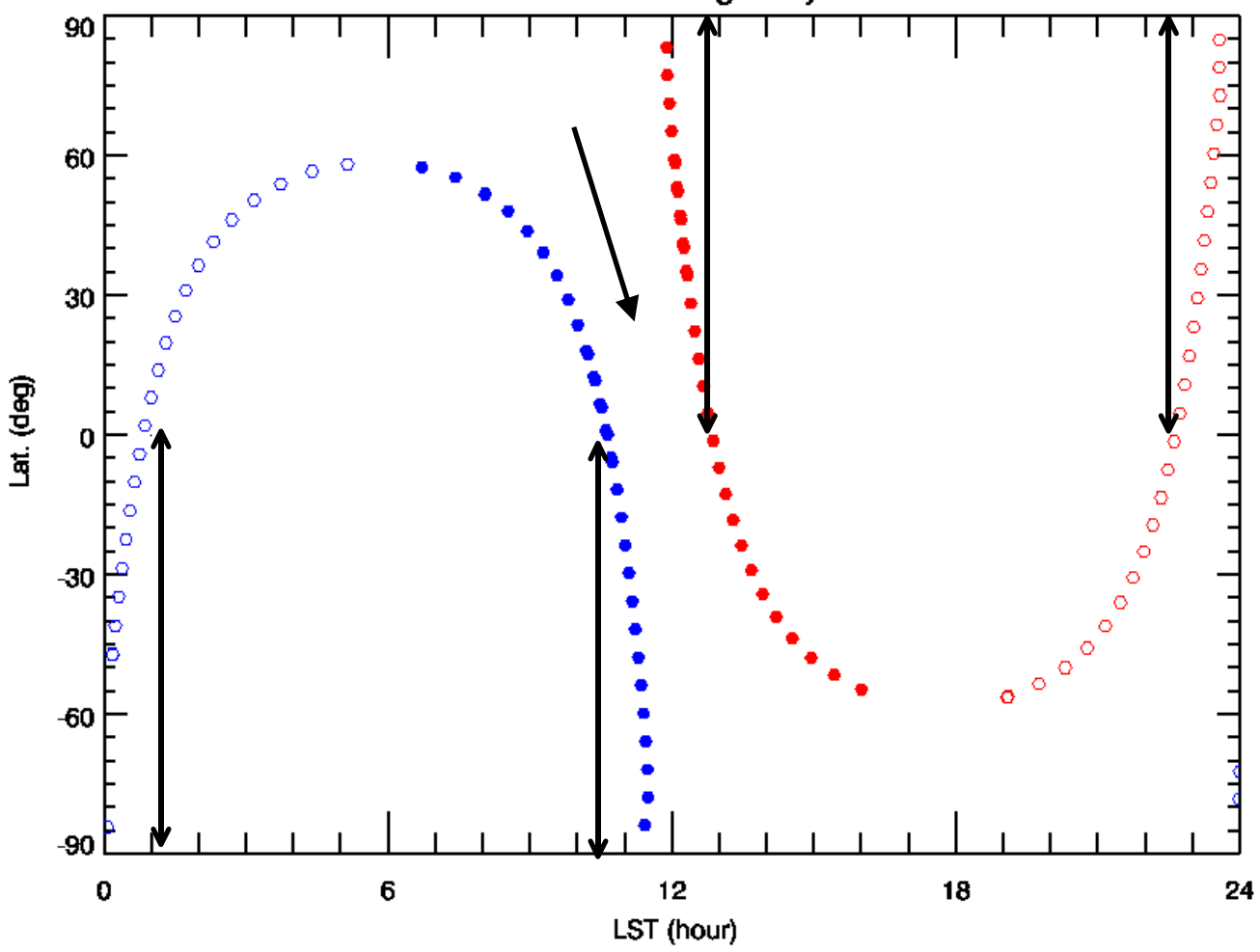

Figure 1.
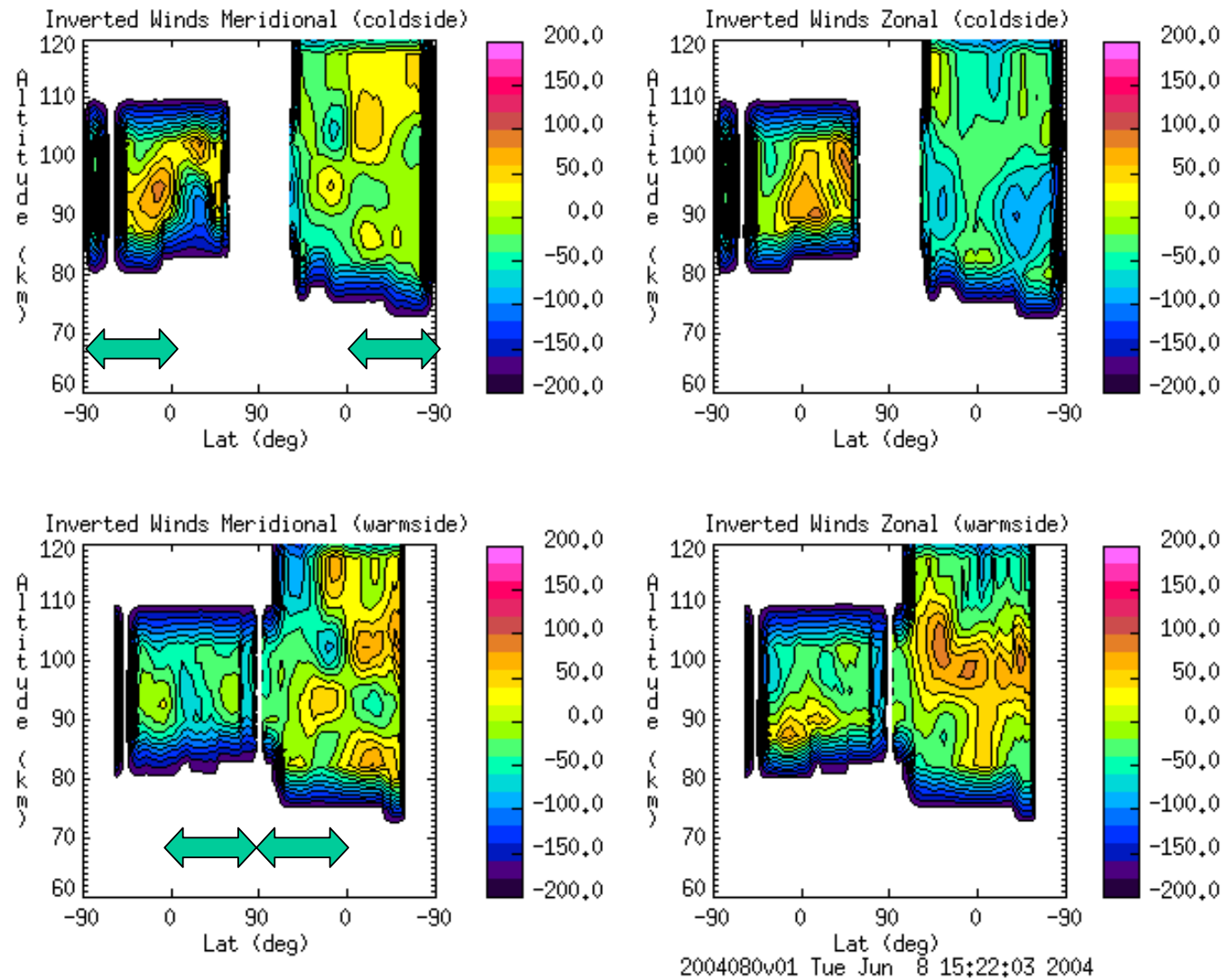

Figure 2. 


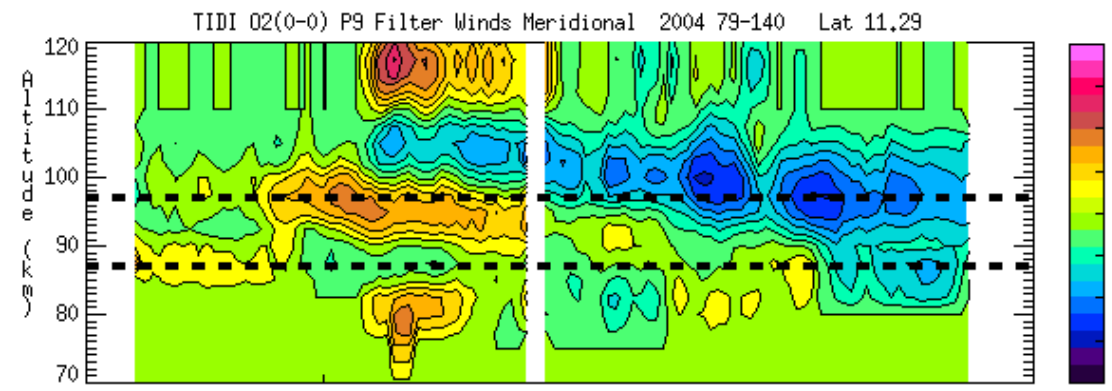

150.0

112.5

$75+0$

37.5

0.0

$-37.5$

$-75.0$

$-112.5$

$-150.0$

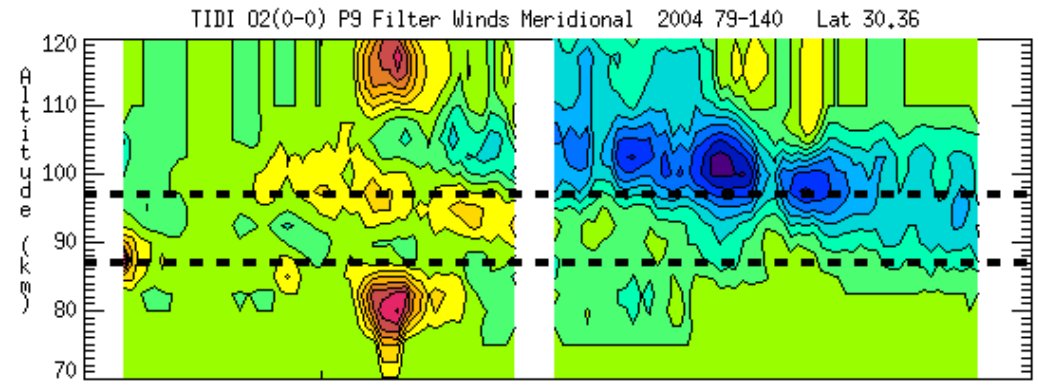

150.0

112.5

75.0

37.5

0.0

$-37.5$

$-75.0$

$-112.5$

TIDI 02(0-0) P9 Filter Winds Meridional 2004 79-140 Lat 44.79

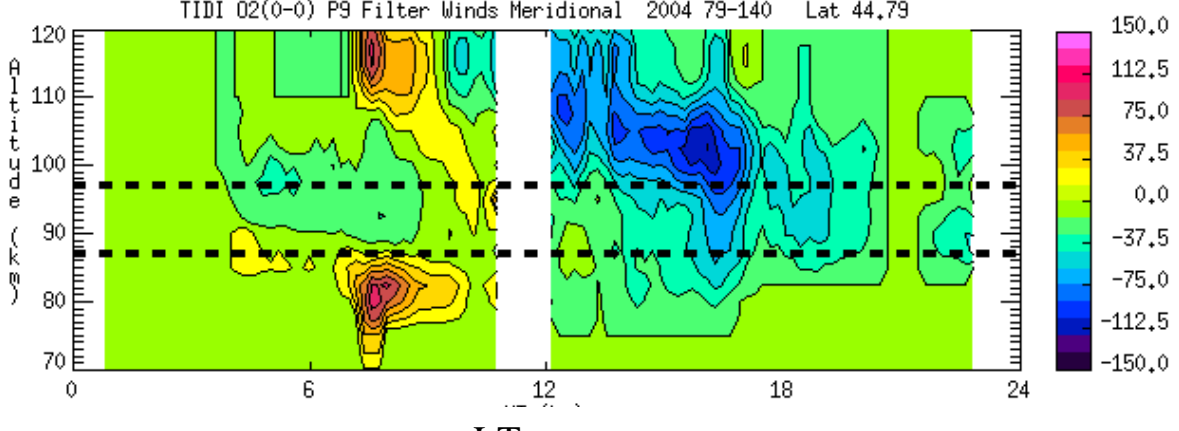

LT

140

dsc

79

140

asc

79

Figure 3. 

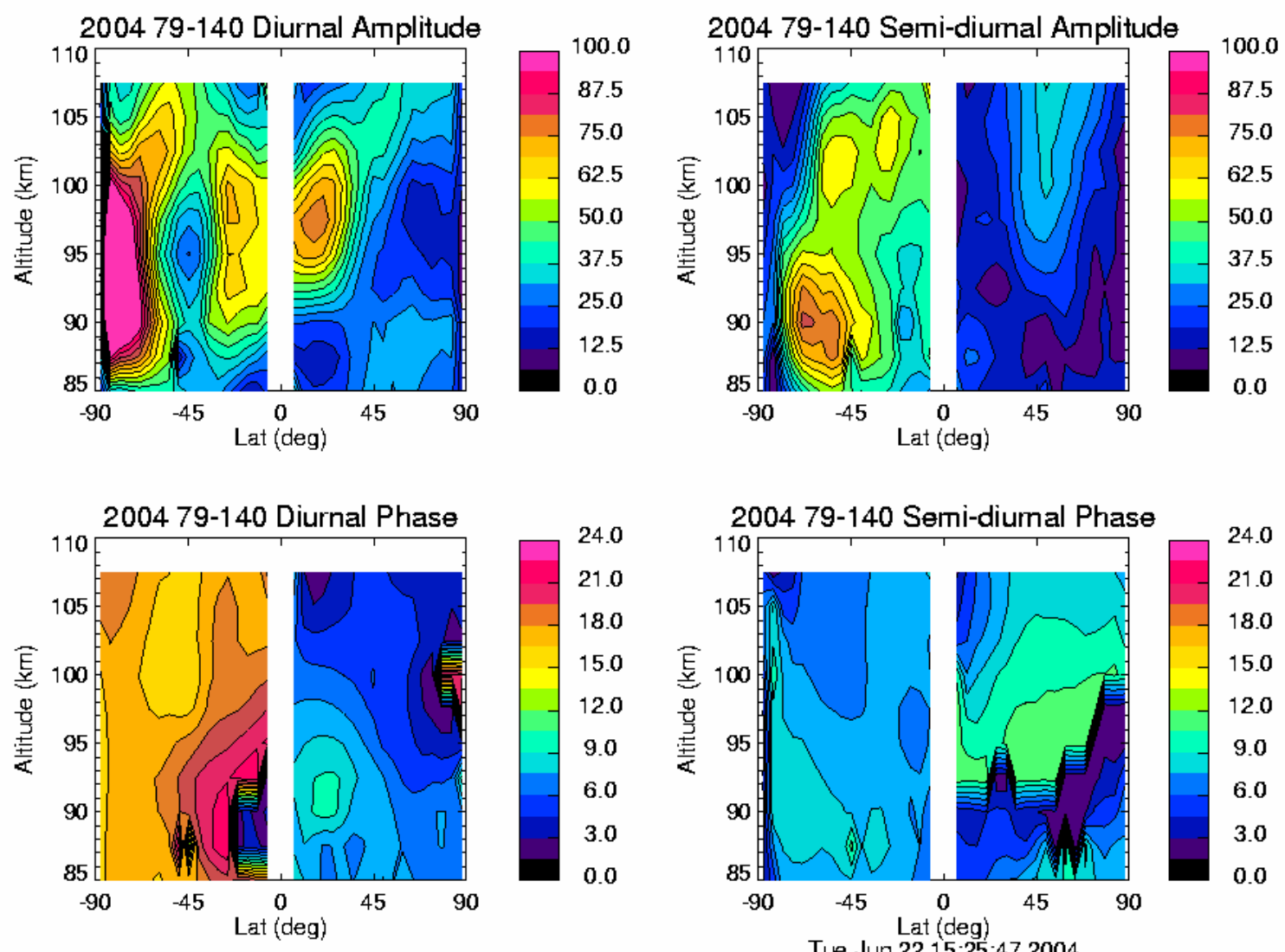

Figure 4.
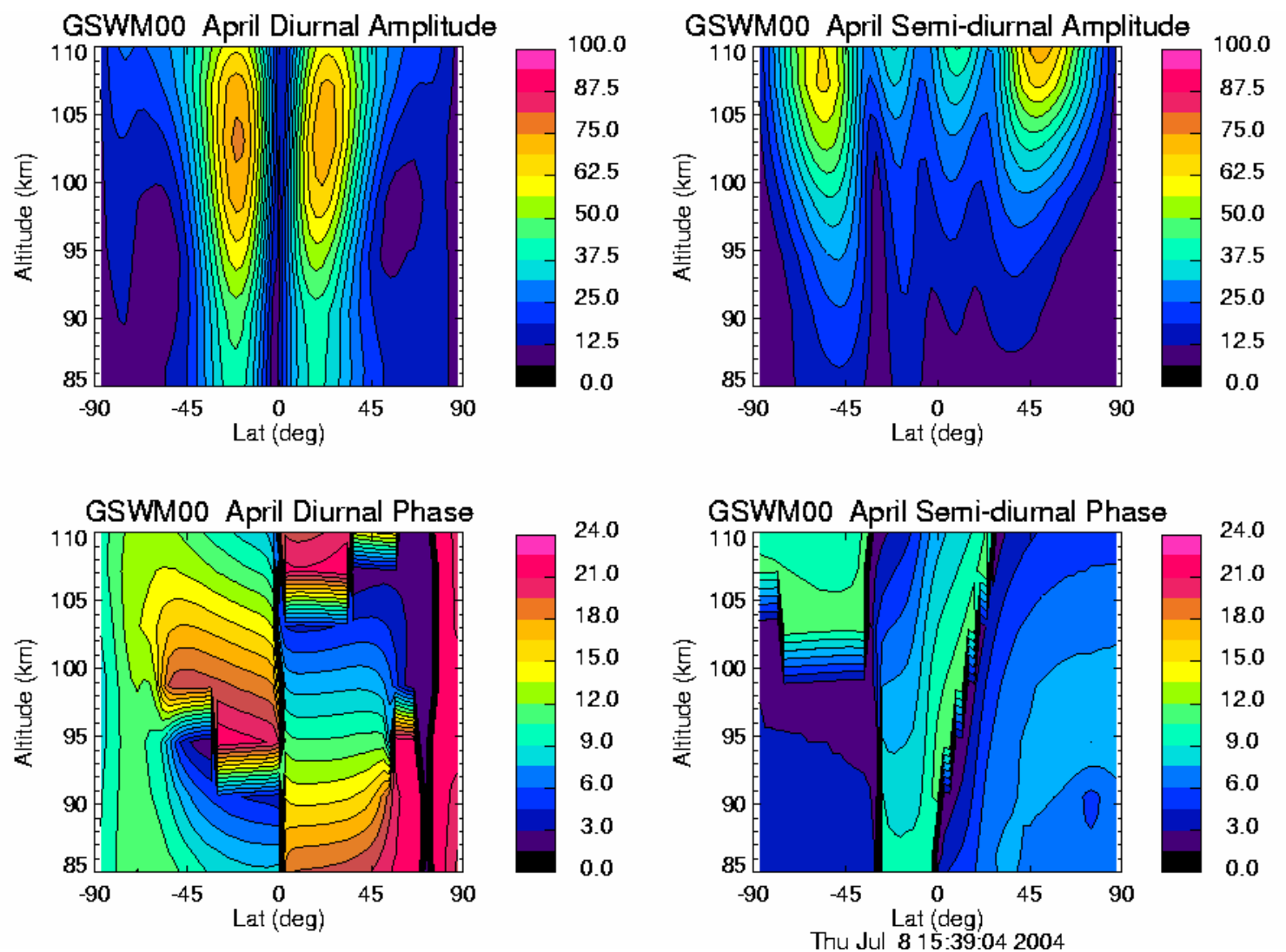

Figure 5. 

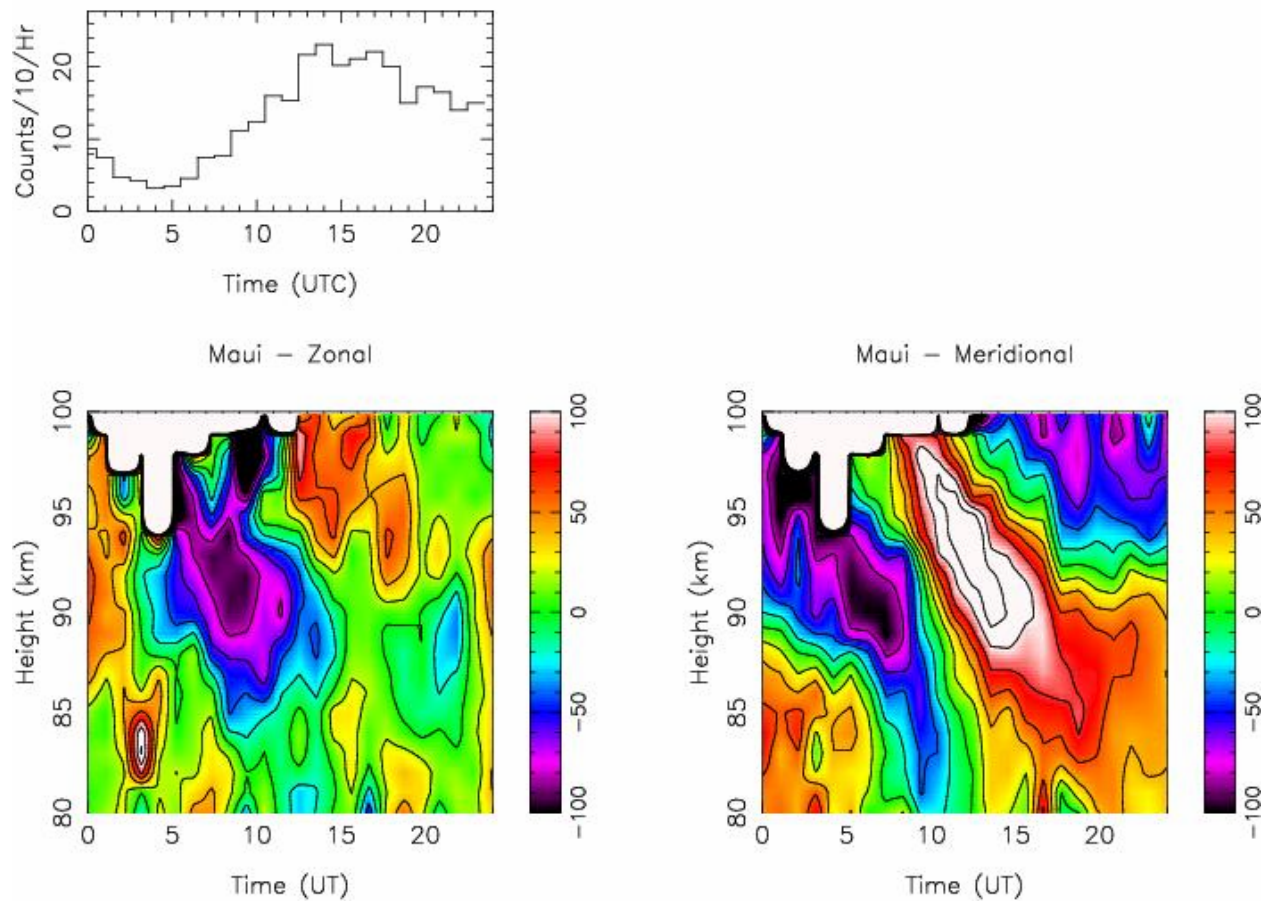

Figure 6.
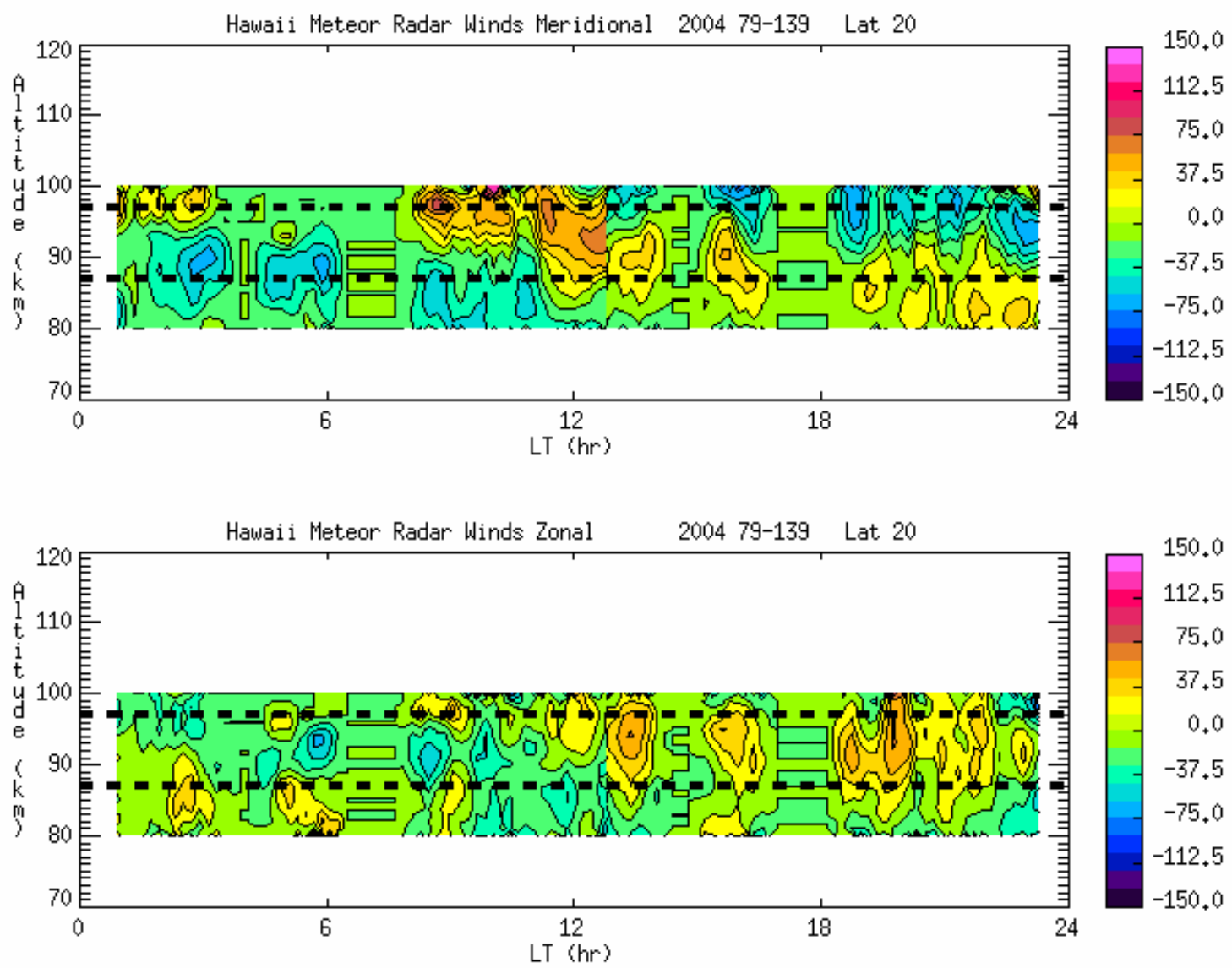

Figure 7. 

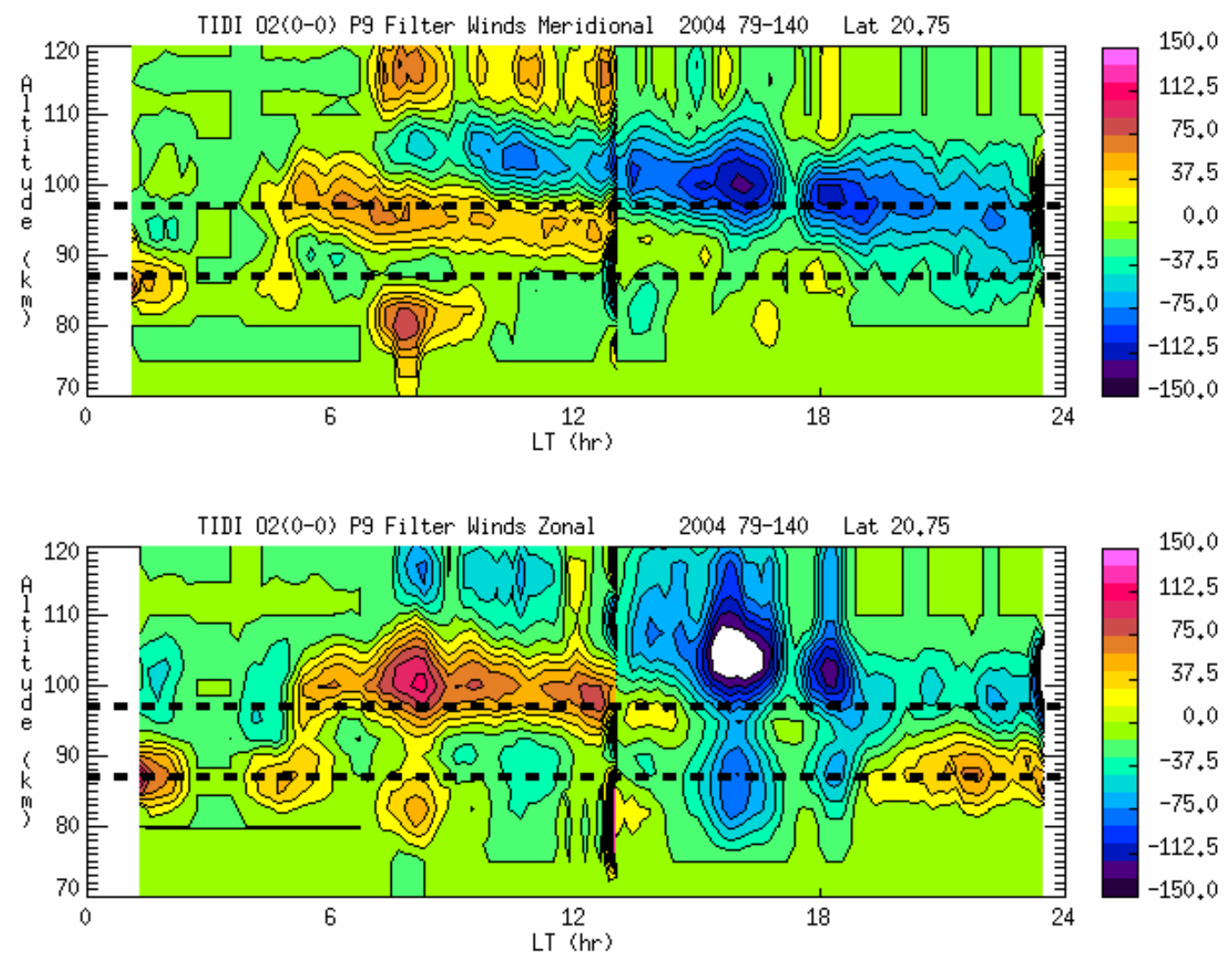

Figure 8 